We think no one in our profession who has had experience in its use would be willing to do without it.

Dr. Watts is deserving of great praise for his persevering course of experiments, which have resulted so favorably to our art. May he reap the abundant reward he deserves. - American Jowrnal of Dental Science.

\title{
ON THE VENOM OF SERPENTS.
}

BY J. GILMAN, A.M., M.D., J..D.

There is much in the history and habits of the reptile tribes, however repulsive they may be in appearance, that is very interesting. During a sojourn of two or three months in the interior of Arkansas, which appears to me to be the paradise of reptiles, I paid some attention to that branch of natural history called ophiology. I found four distinct varieties of rattlesnakes (crotalus), of which the Crotalus Horridus and Crotalus Kirtlandii are by far the most numerous. The former is the largest serpent in North America. The family of moccasin snakes (Colluber) is also quite numerous, there being not less than ten varieties, most of which are quite as venomous as the rattlesnake. By dissecting great numbers of different species I learned that the anatomical structure of the poisoning apparatus is similar in all the different varieties of venomous serpents. It consists of a strong frame-work of bone, with its appropriate muscles in the upper part of the head, resembling and being, in fact, a pair of jaws, but externally to the jaws proper, and much stronger. To these is attached by a ginglymoid articulation, one or more movable fangs on each side, just at the verge of the mouth, capable of being erected at pleasure. These fangs are very bard, sharp, and crooked, like the claws of a cat, and hooked backward, with a hollow from the base to near the point. I have occasionally seen a thin slit of bone divide this hollowmaking two. At their base is found a small sac, containing two or three drops of venom which resembles thin honey. The sac is so connected with the cavity of the fang during its erection, that a slight upward pressure forces the venom into the fang at its base, and it makes its exit at a sinall slit or opening near the point, with considerable force; thus it is carried to the bottom of any wound made by the fang. Unless the fangs are erected for battle, they lie concealed in the upper part of the mouth, sunk between the external and internal jaw bones, somewhat like a pen-knife blade shut up in its handle, where they are covered by a fold of membrane, which encloses them ljke a sheath; this is the vagina dentis. There can be no doubt that these fangs are fiequently broken off or shed, as the bead grows broader, to make room for new ones nearer the verge of the mouth; for, within the vagina dentis of a very large crotalus horridus, I found no less than five fangs on each side-in all stages of formation-the smallest in a half pulpy or cartilaginous state, the next sornething harder, the third still more perfect, and, so on to the main, well-set, perfect fang. Each of these teeth had a welldefined cavity like the main one. Three fangs on each side were frequently found in copper heads, vipers and others. 
The process of robbing serpents of their venom is easily accomplished by the aid of chloroform, a few drops of which stupefies them. If, while they are under its influence, they are carefully seized by the neck, and the vagina dentis held out of the way by an assistant, with a pair of forceps, and the fang be erected and gently pressed upward, the venom will be seen issuing from the fang, and dropping from its point. It may then be absorbed by a bit of sponge, or caught in a vial, or on the point of a lancet. After robbing several serpents in this manner, they were found after two days to be as highly charged as ever with venom of equal intensity with that first taken.

During the process of robbing several species of serpents, I inoculated several small but vigorous and perfectly healthy vegetables, with the point of a lancet well charged with venom. The next day they were withered and dead, looking as though they had been scathed with lightning. In attempting to preserve a few drops of venom, for future experiments, in a small vial with two or three parts of alcobol, it was found in a short time to have lost its venomous properties. But after mixing the venom with aqua ammonia, or spirits turpentine, or oil of peppermint, or of cinnamon, or of cloves, or with nitric or sulphuric acid, it still seemed to act with undiminished energy. It is best preserved, however, for future use by trituration with refined sugar or sugar of milk.

A very fine large cotton-mouth snake, being captured by putting a shoe-string around him, became excessively ferocious, striking at even the crack of a sunall riding whip. Finding himself a prisoner, without hope of escape, he turned his deadly weapons on his own body, striking repentedly his well-charged fangs deeply into his flesh. Notwithstanding this, he was put in a small basket, and carried forward. In one hour after, he was found dead, and no amount of irritation could excite the least indication of life. Four hours after, while removing the skin for preservation, the blood oozed slowly from the vessels in a dissolved state. No violence was done to his snakeship, except what he did to himself.

Another moccasin, shot by a pistol about two inches back of the head, and skinned immediately, gave decided evidence of vitality four hours after being flayed, by writhing the body whenever it was irritated by a scalpel.

A large rattlesnake beheaded instantly, with a hoe, would, an hour and a balf after, strike at anything that pinched its tail. Of several persons who were testing their firmness of nerve, by trying to bold the hand steady while the serpent struck at it, not one could be found whose hand would not recoil in spite of his resolution; and one man, a great bully, by-the-by, was struck on the naked throat with considerable violence by the headless trunk of the serpent, and staggered back, fainted and fell, from terror. Mr. Stewart, of Miss., tells me he once witnessed a similar scene. An old hunter shot a rattlesnake's head off, and after re-loading his gun and standing sone time, he stooped to pull off the rattles, and the bloody but headless trunk of the snake struck him in the temple, and he fainted and fell down with terror.

Seven venomous serpents belonging to five different species were made to fraternize and dwell amicably in one den. A beautiful pair of long 
bodied speckled snakes, known as king-snakes, found to be fangless, and consequently without venom, were duly installed as members of the family. Some uneasiness was perceivable among the older members, but no attempt was made to destroy the intruders, though they might have been killed instanter. The next morning four of the venomous serpents were found to have been destroyed by the king-snakes, and one was still within their coil, and the two remaining ones would make no effort at self-defence. A large rattlesnake seemed stupid and indifferent to his fate. He could not be made to threaten or give warning even with his rattles. The smallest king-snake was afterwards inoculated with the poison of one of the serpents be had destroyed, and died immediately after-thus evincing that they must have exercised some power besides physical force to overcome their fellow creatures.

In short, the results of a great number of experiments performed with the venom of a great variety of serpents, seem to lead to the following conclusions :-

Ist. That the venom of all serpents acts as a poison in a similar manner.

2d. That the venom of some varieties is far more active than that of others.

3d. That a variety of the colluber, known as the cotton-mouth, is the most venomous serpent in Arkansas.

4th. That the venom of serpents destroys all forms of organized life, vegetable as well as animal.

5 th. That alcohol, if brought in contact with the venom, is, to a certain extent, an antidote.

6th. That serpents do possess the power of fascinating small animals, and that this power is identical with mesmerism.

$7 \mathrm{th}$. That the blood of sinall animals, destroyed by the venom of serpents, bears a close resemblance to that of animals destroyed by lightning or hydrocyanic acid; it loses its power of coagulation and cannot be long kept from putrefaction._St. Louis Med. and Surg. Jour.

\section{A SINGULAR CASE-HYDROPHOBIC SYMPTOMS.}

BY J. E. THOMPSON, M.D., OF MIssoURI.

[Conmunicated for the Boston Medical and Surgical Journa].]

March 30, 1854, I was called professionally to see John Connel, ætas 35, an Irish laborer, of good habits and constitution, rather corpulent, and of great muscular strength. Found the patient under much nervous excitement, naked, and walking his room to and fro. Notwithstanding all the windows were raised, and the doors thrown open, he would every few minutes exclaim, "Great God! I am smothering! I am smothering" ! His eyes were red as though under the influence of intoxication ; countenance greatly dejected; pulse 128, small and thready: respiration difficult; bowels distended; skin hot and dry, with a thin, lightcolored coating upon the tongue. No local injury could be found. $1 \mathrm{im}$ mediately threw several pailfuls of ice-water upon his body, which, after a 